\title{
Gallagher, T.M. (2016). DISCERNIMIENTO DE ESPÍRITUS. GUÍA IGNACIANA PARA LA VIDA COTIDIANA. BARCELONA: HERDER
}

\author{
Carlos Alberto Rosas Jiménez
}

1 Magíster en Bioética por la Universidad Libre Internacional de las Américas. Biólogo por la Universidad de los Andes, Colombia. Filósofo, Bachiller canónico en Filosofía y Bachiller en Sagrada Teología por la Universidad Pontificia Bolivariana, Colombia. Docente en la Universidad de la Sabana. Correo electrónico: carlosalbertorosas@ hotmail.com 
Gallagher, T.M. (2016). Discernimiento de espíritus. Guía ignaciana para la vida cotidiana. Barcelona: Herder

Discernimiento de espiritus, como muchos otros libros que comentan los Ejercicios Espirituales de san Ignacio de Loyola, describe lo que se conoce como el discernimiento de espíritus. Sin embargo, se dedica a explicar, ilustrar y, sobre todo, aplicar el discernimiento de espíritus en la experiencia espiritual cotidiana y común de las personas. El autor recalca que en la actualidad existen muchos factores personales y sociales que, impidiendo el cultivo del silencio interior y exterior, aumentan la dificultad de adentrarse en la propia conciencia y, por ende, contribuyen a una profunda resistencia de las personas del mundo de hoy a vivir hacia adentro, es decir, hacia el encuentro consigo mismos. Dado que esta no es una tarea fácil, este libro está dirigido a quienes tengan la valentía -la virtud que quizá más repite el autor a lo largo de todo el libro- de ser espiritualmente conscientes de su vida.

Nuestro autor, el padre Timothy Gallagher, fue ordenado en 1979 como miembro de la congregación de los Oblatos de la Virgen María, una comunidad religiosa dedicada a retiros y formación espiritual, siguiendo los Ejercicios espirituales de san Ignacio. Obtuvo su doctorado en 1983 por la Universidad Gregoriana de Roma, y desde entonces se ha dedicado plenamente a la enseñanza de la tradición espiritual ignaciana y a la dirección espiritual en diversos países del mundo. Es autor de varios libros sobre la enseñanza espiritual de san Ignacio de Loyola y actualmente ocupa la cátedra "San Ignacio para la formación espiritual" en el Seminario Teológico St. John Vianney en Denver, Estados Unidos.

La presente obra está dividida en 14 capítulos con una introducción y un prólogo previos al desarrollo de los capítulos, finalizando con una muy breve conclusión. Los capítulos desarrollan cada una de las 14 reglas del discernimiento que expone san Ignacio en sus Ejercicios Espirituales. Quisiéramos, antes de mencionar algunos aspectos sobre cada una de dichas reglas, destacar algunos interrogantes que plantea el autor sobre la necesidad del conocimiento de sí mismos, y que pueden motivar la profundización en la propia vida espiritual de las personas y la consiguiente lectura de este libro. Podría uno preguntarme entonces si:

[...] ¿Hay alguna situación que me desanime frecuentemente? ¿Alguna situación que suela despojarme de la energía espiritual? ¿ Hay circunstancias en las que, con frecuencia, me invada el miedo? ¿Y circunstancias que 
me agoten? ¿Y circunstancias en las que me sienta espiritualmente desamparado? ¿Hay alguna cosa que parezca disminuir la mayor parte de mi energía para amar y servir a los demás? ¿Hay algo que habitualmente me desanime en la oración? ¿`Y algo que a menudo me haga dudar del amor de Dios? ¿Hay algún patrón recurrente de estas experiencias? (p. 368).

Si se contestó afirmativamente a alguno de estos interrogantes, la lectura de este libro es para usted. Además, podrá encontrar luces a otros interrogantes sobre usted mismo y sobre el avance o retroceso de su vida espiritual.

El recorrido de las 14 reglas comienza con las personas que se alejan de Dios y que, por ende, se acercan a faltas graves que fracturan esa relación con Dios, consigo mismos, con los demás y con el mundo que los rodea; así mismo, se describe cómo actúan en estas personas los espíritus ( $1^{\circ}$. Regla). Posteriormente, considera a las personas que están "en el servicio de Dios nuestro Señor de bien en mejor subiendo" (p. 99) y el modo en que los espíritus obran sobre estas personas ( $2^{\circ}$. Regla). Tras haber descrito los dos tipos de movimientos espirituales (la consolación espiritual y la desolación espiritual $-3^{\circ}$. y $4^{\circ}$. Reglas-, Ignacio da instrucciones para poder resistir a la desolación espiritual - de la $5^{\circ}$. a la $9^{\circ}$. Regla-. Después señala algunas enseñanzas clave para prepararse para la desolación espiritual antes de su comienzo, almacenando en tiempos de consolación espiritual la energía que necesitarán para resistir en el futuro a dicha desolación $-10^{\circ}$. Regla- . En este punto, Ignacio invita a las personas de discernimiento a vivir con equilibrio y madurez espiritual, ni imprudentemente en lo alto durante la consolación espiritual, ni desesperadamente en lo bajo durante la desolación espiritual $-11^{\circ}$. Regla-. Por último, Ignacio se centra en las tentaciones del enemigo, y guía a las personas fieles para que les opongan resistencia desde el comienzo mismo $-12^{\circ}$. Regla-, por medio de la valentía de hablar de las astucias y persuasiones del enemigo con la persona espiritual apropiada $-13^{\circ}$. Regla-. En esta serie de reglas, se alcanza el máximo perfeccionamiento del discernimiento cuando las personas de discernimiento se vuelven capaces de vencer los ataques personalizados del enemigo, antes incluso que este los emprenda $-14^{\circ}$. Regla-. 
Gallagher, T.M. (2016). Discernimiento de espíritus. Guía ignaciana para la vida cotidiana. Barcelona: Herder

De esta manera, el crecimiento espiritual descrito a lo largo de este itinerario de discernimiento es inmenso. Se comienza con la persona que se aleja de Dios y se concluye con la persona que está "en el servicio de Dios nuestro Señor de bien en mejor subiendo" (p. 99), preparada para derrotar al enemigo incluso antes del comienzo de su acción.

Las catorce reglas de san Ignacio constituyen un programa para crecer progresivamente en el discernimiento de espíritus. El esfuerzo humilde y perseverante de vivir de acuerdo con la sabiduría de estas reglas, con la ayuda de un guía espiritual y con confianza en la gracia de Dios, "que siempre es suficiente" (p. 372), va formando poco a poco a una persona con madurez espiritual, capaz de discernir y superar los engaños del enemigo, al tiempo que cumple con fidelidad la voluntad de Dios y crece en el amor. Este es el objetivo del discernimiento de espíritus.

Queremos destacar algunos puntos fundamentales que hacen de este libro una lectura muy aterrizada y encarnada de los Ejercicios Espirituales Ignacianos para el cristiano actual. En primer lugar, el discernimiento de espíritus puede obtenerse de dos formas: como don o carisma del Espíritu, o por medio de la aplicación de las reglas de discernir. El primer camino hacia el discernimiento puede estar simplemente dado por Dios; mientras que el segundo camino hacia el discernimiento, que es mediante el aprendizaje y la aplicación de las reglas del discernimiento, va presentándose gradualmente y a través de la práctica constante (cfr. pp. 376-377). Este segundo camino es el centro de la reflexión de este libro y no pretende ser un libro para fanáticos religiosos ni espiritualoides.

En segundo lugar, el autor insiste en que el punto de partida del discernimiento y la puerta hacia la libertad espiritual ( $C f$ r. pp. $275 ; 299)$ es la decisión de vivir esa constante conciencia espiritual favorecida por los espacios de silencio exterior que contribuyen significativamente al silencio interior. No hay cambios en la vida espiritual sin decisiones firmes, algo opuesto al pensamiento débil y la sociedad líquida del siglo XXI.

En tercer lugar, esa decisión requiere mucha valentía, pues es necesario "procurar permanecer lo suficientemente dentro como para que lo que se mueve espiritualmente en nuestro corazón se haga presente a nuestra 
conciencia" (p. 60). En ese sentido, muchas veces puede ser muy difícil enfrentarse a una herida psicológica que se ha ido acumulando a través de los años en la historia personal de cada uno, cosa que impide a muchos hacer frente a su propia vida espiritual.

En cuarto lugar, queremos destacar aquello que el autor menciona varias veces como la diferenciación entre el "yo" y el "yo-que-reflexionasobre-el-yo-en-desolación" (cfr. 203; 339), ya que en los momentos de desolación espiritual se da la mentira (p. 179) que incluye una falsa identificación entre lo que la persona siente en su desolación y lo que realmente es espiritualmente (p. 155). Sin embargo, es necesario para comprender mejor qué nos pasa en los momentos de desolación espiritual, que nos situemos en la posición del "yo-que-reflexiona-sobreel-yo-en-desolación"; así, podremos ver desde una perspectiva diferente, tomando un poco de distancia de nosotros mismos, y ver la desolación espiritual como parte de un conjunto que incluye la totalidad de nuestra historia personal y nuestra realidad presente.

En quinto lugar, este libro responde a dos dificultades de capital importancia en nuestra sociedad: la de la desesperanza y la del querer controlar todo. Queda increíblemente claro cómo dejar de luchar en la desolación es causa directa de una experiencia de desánimo y desesperanza, las cuales, juntas, conllevan a la desconfianza en Dios y al consiguiente alejamiento de Él. Por otro lado, el deseo de controlar todo en nuestra sociedad y pretender ser dueños del tiempo, de nuestro dinero, ejercer el poder sobre personas o estructuras nos lleva a tener siempre "la sartén por el mango". No obstante, únicamente cuando renunciamos a controlar la obra de Dios en nuestro corazón, descubrimos que la oscuridad en nuestro interior se disipa gradualmente (cfr. p. 186).

A pesar de la claridad y fluidez que se puede tener en la lectura de este libro, es llamativo que los ejemplos que pone el autor son un poco ingenuos o demasiado simples, pues cuando habla en algunas partes del libro sobre los momentos de desolación espiritual, comenta distracciones en la oración, desánimo en la labor apostólica o algunas dudas sobre si seguir o no la vocación al sacerdocio. No obstante, queremos enfatizar que, si bien son una manera de ilustrar cada una de las reglas del discernimiento de espíritus, 
Gallagher, T.M. (2016). Discernimiento de espíritus. Guía ignaciana para la vida cotidiana. Barcelona: Herder

son ejemplos que no ilustran muchas de las crisis o fuertes desolaciones que pueden experimentar laicos, religiosos o sacerdotes.

Las grandes desolaciones son cuando nos peleamos con Dios, cuando le reclamamos porque no comprendemos su plan con nosotros; cuando no nos parece la manera como avanzan las cosas en nuestras vidas o cuando vemos que después de muchos años de servicio, oración, entrega amorosa y generosa a los demás no vemos los frutos o vemos que a otros que hacen menos o casi nada de esto, aparentemente les va mejor. Ahí es cuando realmente nos desanimamos, nos desilusionamos o nos enfadamos con Dios.

Pareciera que el autor tiene un cierto temor de hablar claro de estas experiencias como si estuviera mal vivirlas o pasar por ellas; siendo que quizá son más comunes de lo que parece. Además, el autor menciona que esas desolaciones espirituales duran unas horas, días o máximo semanas. Lo cierto es que pueden durar varios años, con estadios prolongados de desánimo y desesperanza; y ahí es cuando realmente está el reto de la utilización de las reglas ignacianas de discernimiento, porque podría parecer que no sirven. El autor hubiera podido poner más ejemplos de esto último para evidenciar que sí son de gran utilidad incluso en esas profundas desolaciones espirituales.

Finalmente, quisiéramos justamente repetir con el autor que todo crecimiento en general lleva tiempo, y el crecimiento en el discernimiento no es la excepción a esta ley universal. Así que el progreso en la capacidad de llevar una vida discernida espiritualmente se da a través de la continuidad en la oración, en los esfuerzos, en la conversación con un guía espiritual, y en todos los medios que Ignacio describe en sus reglas ( $c f r$. p. 376), cosa muy contraria a la cultura de lo provisorio o del inmediatismo en el que vivimos sumergidos.

Concluimos simplemente que la temática del libro está creativa y sistemáticamente adaptada para quienes deseen ahondar más en cómo llevar a la vida cotidiana y a su esfuerzo por alcanzar la santidad, las enseñanzas del Evangelio, teniendo como guía los Ejercicios Espirituales de san Ignacio de Loyola. 